\title{
A inclusão das pessoas com deficiência: panorama inclusivo no ensino superior no Brasil e em Portugal
}

\section{Inclusion of people with disabilities: Inclusive panorama in higher education in Brazil and Portugal}

\author{
Carlos Eduardo Candido Pereira* \\ Cristina Maria Pinto Albuquerque ${ }^{* *}$
}

\begin{abstract}
RESUMO
A inclusão de pessoas com deficiência se efetivou na sociedade atual devido às ações e aos discursos políticos a partir dos anos 1990. O fato é que o assunto já é uma questão de direitos conclamados por ONGs, famílias e pelas próprias pessoas com deficiência desde meados do século XX e que se consolidam, de modo mais específico, por meios legais. Um destes universos de afirmação legal é a universidade. Dado isso, este estudo parte de uma análise bibliográfica com uso de leis, pois considera a política de pessoas com deficiência relacionadas à inclusão na universidade, no contexto brasileiro e no português, com perspectivas de questionar a sua validade. Trata-se de um momento de experiências e reflexão frente ao debate das políticas de inclusão. Dessa forma, as análises possibilitam inferir que, apesar de todas as conquistas legais, a prática da cidadania ainda se encontra confusa tanto no Brasil quanto em Portugal, porém, com avanços às barreiras atitudinais, arquitetônicas e de comunicação, o que tenciona a promoção de mais ações neste sentido.
\end{abstract}

Palavras-chave: Deficiência. Educação. Trabalho. Políticas públicas. Brasil. Portugal.

DOI: $10.1590 / 0104-4060.52923$

* Universidade Estadual Paulista (UNESP). Faculdade de Ciências e Letras. Araraquara, São Paulo, Brasil. Rod. Araraquara-Jaú, Km 1. Bairro Machados. CEP: 14800-901. E-mail: candido_unesp@yahoo.com.br

** Universidade de Coimbra (UC). Faculdade de Psicologia e de Ciências da Educação. Coimbra, Portugal. R. Colégio Novo 10A, 3001-802. E-mail: crisalbuquerque@fpce.uc.pt 


\begin{abstract}
The inclusion of people with disabilities has been taking hold in today's society due to political actions and speeches since the 1990s. The fact is that the issue is already a matter of rights called for by NGOs, families and disabled people themselves since the middle of the $20^{\text {th }}$ century and which are consolidated, in a more specific way, by legal means. One of these universes of legal affirmation is the university. With these considerations, this study starts from a bibliographic analysis with the use of laws, considering the policy towards people with disabilities related to inclusion in the university in the Brazilian and Portuguese context, with perspectives to question the validity of this inclusion. It is a moment of experience and reflection in the context of the inclusion policy debate. Given this, the analyses make it possible to infer that, despite all legal achievements, the practice of citizenship is still confusing both in Brazil and Portugal, but with advances in attitudinal, architectural and communication barriers, which tends to promote more actions towards inclusion.
\end{abstract}

Keywords: Disability. Education. Work. Public policies. Brazil. Portugal.

\title{
Primeiras palavras...
}

Nos últimos anos, diversos autores vêm acentuando a forte conexão entre deficiência e discriminação, colocando, no primeiro plano da análise, a concessão da deficiência como uma construção social e simbólica (TURMUSANI, 2002; FONTES, 2009). A ideia de uma sociedade "deficientizadora", que gera dinâmicas de opressão e de exclusão, emerge, na verdade, na Grã-Bretanha e nos Estados Unidos da América, nas décadas de 1960/70, a partir de movimentos sociais promovidos pelas próprias pessoas com deficiência e pelas associações que as representavam. Esses movimentos enfatizavam, sobretudo, as insuficiências dos modelos sociais, por referência às necessidades específicas daqueles grupos, e reivindicavam o direito à utilidade, ao reconhecimento da diferença não excludente e à participação social e econômica equitativa. As preocupações associadas aos processos de autonomização, emancipação e inclusão substantiva das pessoas com deficiência passam assim a ser destacadas, não apenas como prioridades sociais, mas sobretudo como objetivos políticos concretizados em esferas diferenciadas. A igualdade de oportunidades de acesso e de frequência da escola, em particular do ensino superior, como direitos de cidadania centrais e como instâncias promotoras de mobilidade social e de inclusão, configuram-se, nesse sentido, como desideratos essenciais. 
A palavra "inclusão" nos permite inferir uma gama de diversos significados e sinônimos, como: colocar, integrar, inserir, incorporar, envolver, dentre outros. Não é nossa pretensão aprofundar a etimologia dessas palavras; porém, vale ressaltar que, na história do cuidado ou da proteção das pessoas com deficiência, tais palavras foram usadas em vários contextos e com vários sentidos até chegar a uma denominação comum dada pela Lei, confirmada nas políticas globais sobre a inclusão do século XX.

No que tange à legislação ou à política, ainda no século XX, fizeram-se presentes, por exemplo, as "ações afirmativas". Nessa direção, para Santos (2005), estas ações podem ser interpretadas como medidas especiais e temporárias, tomadas ou determinadas pelo Estado, espontânea ou compulsoriamente, com o objetivo de eliminar desigualdades históricas acumuladas, garantindo a igualdade de oportunidades e tratamento, bem como de compensar perdas provocadas pela discriminação e marginalização, decorrentes de motivos raciais, étnicos, religiosos, de gênero, dentre outros.

Para Sassaki (2006), mesmo com o avanço das leis e a construção de ambientes de socialização em espaços específicos, como o mercado de trabalho, a escola e as universidades, ainda há a predominância de barreiras para as pessoas com deficiência, tais como: as atitudinais (não há uma compreensão do que é ser uma pessoa com deficiência, bem como suas limitações e possibilidades), a falta de ambiente acessível (a inclusão da pessoa com deficiência em certos espaços que às vezes não leva em conta a sua condição), a má vontade em efetuar acomodações razoáveis (as adaptações são feitas no cotidiano ou mesmo nunca são feitas; em termos arquitetônicos isso é bastante evidente), a falta de informação sobre recursos de reabilitação e técnicas de desenvolvimento (sobretudo ao se tratar de organização para o trabalho deste público).

Sobre a inclusão em espaços escolares em toda a trajetória que vai do básico ao universitário concorda-se com aquilo que Mittler (2003, p. 34) apregoa:

A inclusão implica uma reforma radical nas escolas em termos de currículo, avaliação, pedagogia e formas de agrupamento dos alunos nas atividades de sala de aula. Ela é baseada em um sistema de valores que faz com que todos se sintam bem-vindos e celebra a diversidade que tem como base o gênero, a nacionalidade, a raça, a linguagem de origem, o background social, o nível de aquisição educacional ou a deficiência.

É possível compreender da referida citação, em concordância com Candido Pereira (2010), que, no contexto deste novo século, a escola precisa se modificar 
para ser inclusiva, não apenas às pessoas com deficiência, mas também a todos, indistintamente. A inclusão exige o envolvimento da escola no conjunto social amplo, por isso, neste artigo, quando se refere à escola se pensa em todos os espaços em condição de educação e ensino em sua amplitude.

Ainda na interpretação de Mittler (2003), a inclusão é baseada num sistema de valores que faz com que todos se sintam bem-vindos e que celebra a diversidade, cuja base é o gênero, a nacionalidade, a raça, a linguagem, a origem social, o nível de aquisição educacional ou a deficiência.

Brasil e Portugal, bem como outros países do mundo, têm alterado suas legislações nas Constituições Nacionais e Leis de Bases da Educação - em prol da inclusão das pessoas com deficiência. Isso foi oriundo da participação de governos em eventos internacionais como a Conferência Mundial de Educação Para Todos, na Tailândia (1990), e a Conferência de Salamanca, na Espanha (1994). Destaca-se ainda o Ano Internacional da Pessoa com Deficiência, promovido pela ONU, em 1981, que foi a base para a organização de eventos como os mencionados.

Ainda assim, a referência ao tipo de classificação da deficiência é diferente entre Brasil e Portugal. Para Candido Pereira (2016), em Portugal, leva-se em consideração a Classificação Internacional de Funcionalidades (CIF), enquanto no Brasil, além da citada classificação (que é usada para apontar a condição médica da deficiência), utiliza-se a legislação para compreender o que é a deficiência, tal como se apresenta no Decreto Federal no 3.298 (BRASIL, 1999), Decreto Federal $n^{\circ}$ 5.296/2004 (BRASIL, 2004) e o recém-promulgado Estatuto da Pessoa com Deficiência, Lei Federal no 13.146/2015 (BRASIL, 2015).

Como será visto adiante há diferenças entre as formas de ingresso e de acesso entre as universidades brasileiras e portuguesas. Apesar das leis de assistência, não há ainda nenhuma forma de cotas para o acesso ao ensino superior às pessoas com deficiência entre os países referidos.

Por último, vale apontar que, para Habermas (1998), a distinção entre a intencionalidade legal e as formas de a operacionalizar pode ser constantemente colocada em evidência, visto que nem sempre as sociedades se configuram ideais na relação entre teoria e práxis da lei. Esse fato dá suporte para traçar considerações e reflexões sobre as leis de inclusão às pessoas com deficiência, bem como questionar sua validade ao ensino superior.

Procuraremos assim no presente artigo destacar, em primeiro lugar, o modo como a problemática da inclusão de pessoas com deficiência, na sociedade e no ensino superior, em particular, se configura na lei e nas práticas que a mesma autoriza e impulsiona em Portugal e no Brasil. Num segundo momento, refletiremos sobre as ideologias e modelos analíticos subjacentes a algumas orientações políticas nesse domínio, procurando perspectivar de que modo, 
por via da linguagem e das percepções que as políticas traduzem, a deficiência se constrói e, como tal, também pode se desconstruir social e politicamente.

\section{A inclusão no ensino superior: panorama português}

Portugal, em 2013, tinha uma população residente de 10.457 .295 pessoas, sendo 636.059 consideradas como pessoas com deficiência. O quadro a seguir mostra a porcentagem de pessoas por tipo de deficiência.

QUADRO 1 - TIPO DE DEFICIÊNCIA EM PORTUGAL

\begin{tabular}{|l|l|r|}
\hline \multirow{3}{*}{ ANO } & \multicolumn{2}{|c|}{ TIPOS DE DEFICIÊNCIA } \\
\hline \multirow{4}{*}{2001} & Auditiva & 84.172 \\
\cline { 2 - 3 } & Visual & 163.569 \\
\cline { 2 - 3 } & Motora & 156.246 \\
\cline { 2 - 3 } & Mental & 70.994 \\
\cline { 2 - 3 } & Paralisia Cerebral & 15.009 \\
\cline { 2 - 3 } & Outra Deficiência & 146.069 \\
\cline { 2 - 3 } & Total & 636.059 \\
\hline
\end{tabular}

FONTE: PORDATA (2013) adaptado de Candido Pereira (2016).

A deficiência motora e a visual são as de maior incidência em comparação com outros tipos, como a auditiva, a mental e a paralisia cerebral. Estes tipos de deficiência podem ser compreendidos como situações de incapacidade. Inúmeros casos de deficiência motora encontram-se associados a ex-combatentes da guerra colonial, na África, que persistiu de 1961 a 1974.

É importante destacar que, desde 1986, a história de Portugal acontece concomitantemente com a da Comunidade Europeia, em razão da obrigatoriedade de ter que adotar diretrizes, as quais os Estados da União Europeia são obrigados a traduzir dentro de suas legislações nacionais enquanto mecanismo político. Ainda assim, a garantia de igualdade de direitos e de oportunidades, bem como o compromisso dos poderes públicos para a sua concretização, encontra-se consignada, desde 1976, na lei fundamental do país. A Constituição da República Portuguesa no período de democratização pós 1974 traduz assim, no seu artigo 71: 
1. Os cidadãos portadores de deficiência física ou mental gozam plenamente dos direitos e estão sujeitos aos deveres consignados na Constituição, com ressalva do exercício ou do cumprimento daqueles para os quais se encontrem incapacitados.

2. O Estado obriga-se a realizar uma política nacional de prevenção e de tratamento, reabilitação e integração dos cidadãos portadores de deficiência e de apoio às suas famílias, a desenvolver uma pedagogia que sensibilize a sociedade quanto aos deveres de respeito e solidariedade para com eles e a assumir o encargo da efectiva realização dos seus direitos, sem prejuízo dos direitos e deveres dos pais ou tutores.

3. O Estado apoia as organizações de cidadãos portadores de deficiência. (PORTUGAL, 1976, não pág.).

Por ser uma legislação, ocorrida na década de 1970, é possível destacar o pioneirismo português às políticas de inclusão que entraram na agenda mundial duas décadas mais tarde. Além da Constituição Portuguesa podem ser mencionados outros normativos que procuram criar condições, desde logo formais, para o acesso das pessoas com deficiência aos diversos direitos inerentes ao seu estatuto de cidadania e aos processos que visam efetivá-los, como: a Lei ${ }^{\circ}$ 9/1989 (revogada pela Lei no 38/2004) - Lei de Bases da Prevenção e da Reabilitação e Integração das Pessoas com Deficiência; a Lei Anti-Discriminação das Pessoas com Deficiência (Lei n ${ }^{\circ}$ 46/2006, de 28 de Agosto); a Resolução da Assembleia da República $n^{\circ} 56 / 2009$, que aprovou a convenção Sobre os Direitos das Pessoas com Deficiência da Convenção de Nova Iorque de 2007; o $1^{\circ}$ PAIPDI (Plano de Integração das Pessoas com Deficiência e Incapacidade - 2006 a 2009) e a Resolução do Conselho de Ministros nº 97/2010, que trata sobre a Estratégia Nacional da Pessoa com Deficiência.

Em todas essas legislações portuguesas, segundo Fontes (2009), o Estado assume a sua responsabilidade de cuidado em serviços de habilitação e reabilitação, saúde, educação e proteção social, procurando minimizar o ciclo vicioso entre incapacidade, discriminação negativa e exclusão (ou mesmo, em muitos casos, pobreza) que pode existir numa sociedade orientada apenas para pessoas sem deficiências.

Em comparação ao Brasil, em Portugal existe um acervo quantitativo menos volumoso de legislação específica às pessoas com deficiência. O PAIPDI, por exemplo, tem uma visão mais integrada sobre as questões da deficiência, mas o uso do conceito de incapacidade (disability) evidencia a perspectiva medicalizada e personalizada na compreensão da deficiência. Para Candido Pereira (2016), a incapacidade (disability) mencionada pelo PAIPDI refere-se à disfuncionalidade no conjunto dos seus diferentes níveis: deficiências, limitações 
da pessoa na atividade e restrições de participação, e não apenas a um dos seus aspectos. Dessa forma,

[...] quer se trate da definição de critérios de elegibilidade referentes à concessão de benefícios, ou da formulação de regulamentos de acesso a tecnologias de apoio, ou da definição de normas sobre política de habitação ou de transportes adaptados para indivíduos com incapacidades no domínio da mobilidade, no domínio sensorial ou no domínio cognitivo, a CIF estabelece o enquadramento para uma política social abrangente e coerente, relacionada com a incapacidade, podendo servir como um instrumento técnico de utilidade inquestionável para que se uniformizem os critérios avaliativos que Portugal aplica. (PORTUGAL, 2006, p. 19).

A educação portuguesa tem como lei de referência a Lei de Bases do Sistema Educativo, Lei ${ }^{\circ}$ 46, de 14 de outubro de 1986 (PORTUGAL, 1986), que já, no seu artigo $3^{\circ}$, assegura que seu sistema educativo se organiza de forma a respeitar a diferença, as personalidades e os projetos individuais da existência, bem como da consideração e valorização dos diferentes saberes e culturas.

Nesse sentido, no artigo 19, destaca e reconhece a Educação Especial como modalidade da educação escolar. Com isso, no artigo seguinte, vale apresentar os objetivos desta modalidade, a saber:

No âmbito dos objectivos do sistema educativo, em geral, assumem relevo na educação especial:

a) o desenvolvimento das potencialidades físicas e intelectuais;

b) a ajuda na aquisição da estabilidade emocional;

c) o desenvolvimento das possibilidades de comunicação;

d) a redução das limitações provocadas pela deficiência;

e) o apoio na inserção familiar, escolar e social de crianças e jovens deficientes;

f) o desenvolvimento da independência a todos os níveis em que se possa processar;

g) a preparação para uma adequada formação profissional e integração na vida activa. (PORTUGAL, 1986).

Tal como em sua Constituição, no que se refere à sua legislação educacional, Portugal também se adiantou aos discursos mundiais de inclusão ocorridos 
a partir dos anos 1990. Ainda assim, as medidas direcionadas para as pessoas com deficiência têm-se caracterizado em Portugal pela setorialização - uma "política a conta gotas", como refere Fontes (2009) - e pela orientação excessivamente individualizada para as necessidades dos deficientes e menos para os seus direitos efetivamente concretizados.

Sobre o ensino superior português, ele é um pouco diferente em comparação ao do Brasil. Isso se observa com mais atenção em termos de financiamento. As universidades portuguesas, mesmo as públicas, cobram sempre taxas de matrículas para anos letivos e propinas mensais (mensalidades) para os alunos (só o ensino obrigatório público é gratuito). Nesse aspecto, a política de ordem mais assistencial ao aluno com incapacidade é conferida pelo despacho $\mathrm{n}^{0}$ 7031-B/2015, conhecido como Estatuto Especial, que no artigo 24 apresenta:

Beneficiam de estatuto especial na atribuição de bolsa de estudo os estudantes bolseiros portadores de deficiência física, sensorial ou outra, nos termos legais em vigor, com um grau de incapacidade igual ou superior a $60 \%$, devidamente comprovada através de atestado de incapacidade passado por junta médica. (PORTUGAL, 2015).

Desse modo, as pessoas com deficiência que não estão enquadrados nos $60 \%$, atribuídos na lei, são excluídas. Em outras palavras, a própria legislação cria um filtro que afasta uma parte da população, que vai ficar excluída se não cumprir nenhum outro critério previsto na lei, nomeadamente, ter recursos econômicos escassos, comprovados sob condição de recursos (i. e, prova documental de insuficiência de ativos financeiros para a frequência do ensino superior).

Vale ainda ressaltar sobre o ensino superior em Portugal, dois objetivos da declaração de Bolonha, de 1999: primeiro o que incentiva à mobilidade estudantil, por etapas, em exercício útil de livre circulação, ou seja, dentro da comunidade europeia um discente tem a possibilidade de realizar um período de estudos em país diferente ao da universidade de origem. O segundo objetivo aborda a adoção de um sistema em ciclos de estudos baseado em três ciclos articulados: o $1^{\circ}$ ciclo, a licenciatura, com a duração mínima de 3 anos, e a pós-licenciatura ( $2^{\circ}$ ciclo-mestrado e $3^{\circ}$ ciclo-doutorado), sendo possível após a finalização dos estudos do primeiro. Em termos práticos, o grau atribuído depois de terminada a primeira fase (licenciatura) deverá ser considerado como sendo um nível de habilitações apropriado para ingressar no mercado de trabalho europeu. A segunda fase deverá conduzir ao grau de mestre e/ou doutor, como em muitos países europeus. 
Somado a isso, é interessante conhecer a possibilidade das mobilidades entre as universidades, fato que possibilita sistemas de auxílios estudantis como o Erasmus Mundus. Este programa permite uma rotatividade e intercâmbio muito interessante aos estudantes dos países europeus.

De acordo com Candido Pereira (2016), nenhum outro objetivo da Declaração de Bolonha, por sua vez, faz menção ao público com deficiência, mesmo a outro grupo, raça e etnia. Fato este que pode possibilitar espaços de investigação na comunidade europeia.

\section{A inclusão no ensino superior: panorama brasileiro}

A inclusão na educação superior brasileira, em termos de política e leis, tem destaque a partir da Constituição Federal (BRASIL, 1988), porém, no que tange aos princípios de igualdade e equidade, alguns são oriundos dos anos 2000. Momento em que o governo brasileiro se dedicou mais à questão da diversidade no ensino superior. De acordo com Moehlecke (2004, p. 477):

Com relação a permanência no Ensino Superior, as ações abrangem basicamente, a concessão de bolsas vinculadas à participação em programas e projetos que promovem uma reflexão sobre políticas de diversidade [...]. Destacam-se ainda os programas de formação de professores abrangendo temas como educação indígena, a educação de gênero e a orientação sexual e as relações étnico-raciais.

Isso pode ser elucidado em razão das políticas de ampliação do ensino superior que tiveram em suas ações, não apenas as pessoas com deficiências, mas os grupos minoritários sob a ótica da diversidade. Vale destacar que, de modo diferente ao do processo de Bolonha - que permite ao estudante uma profissão após conclusão do terceiro ano de curso (principalmente em licenciaturas) - no caso do Brasil, é necessária a finalização do estudo em curso específico.

No Brasil contemporâneo pode ser apontado que a forma de ingresso às universidades ainda está em vias de se padronizar. Atualmente passa-se a aceitar as notas obtidas no Exame Nacional do Ensino Médio (ENEM) para ingresso em universidades públicas e algumas universidades particulares. Com as notas deste exame, o candidato pode requerer bolsas do Fundo de Financiamento 
Estudantil (FIES), principalmente nas universidades particulares, bem como solicitar ingresso em universidades pelo Sistema de Seleção Unificada (Sisu). Ainda há, porém, instituições que fazem exames seletivos, provas de conteúdo e vestibulares.

Vale retomar algumas legislações do ensino superior brasileiro que culminam em políticas de inclusão. Assim sendo, a avaliação das universidades é realizada por meio de um sistema chamado Sistema Nacional de Avaliação da Educação Superior (SINAES), criado pela Lei $n^{0}$ 10.861/2004 (BRASIL, 2004). Este avalia todos os aspectos que giram em torno do ensino, pesquisa e a extensão, bem como, a responsabilidade social, o desempenho dos alunos, a gestão da instituição, o corpo docente, as instalações das universidades e vários outros aspectos (sendo o da inclusão de pessoas ainda desconhecido).

O Programa Universidade Para Todos (PROUNI) foi institucionalizado pela Lei Federal $n^{\circ}$ 11.096/2005 (BRASIL, 2005). A finalidade dele é a concessão de bolsas de estudo integrais e parciais em cursos de graduação e sequenciais de formação específica em instituições de ensino superior privadas.

A Reestruturação e Expansão das Universidades Federais (REUNI), criada pelo Decreto $\mathrm{n}^{\circ}$ 6.096/2007 (BRASIL, 2007), é uma das ações que integram o Plano de Desenvolvimento da Educação no Brasil (PDE). Com ele, o governo brasileiro tomou uma série de medidas para retomar o crescimento do ensino superior público, criando condições para que as universidades federais promovessem a expansão física, acadêmica e pedagógica da rede federal de educação superior. Suas ações contemplam o aumento de vagas nos cursos de graduação, a ampliação da oferta de cursos noturnos, a promoção de inovações pedagógicas e o combate à evasão, entre outras metas, que têm o propósito de diminuir as desigualdades sociais no país.

O Programa mais direcionado para as pessoas com deficiência no ensino superior é o Programa de Acessibilidade na Educação Superior ${ }^{1}$ (Incluir), que propõe ações que garantam o acesso pleno deste público às instituições federais de ensino superior. O Incluir tem como objetivo principal fomentar a criação e a consolidação de núcleos de acessibilidade nas Instituições Federais de Ensino, os quais respondem pela organização de ações institucionais que garantam a integração de pessoas com deficiência na vida acadêmica, eliminando barreiras comportamentais, pedagógicas, arquitetônicas e de comunicação.

Segundo informações institucionais do próprio Programa Incluir, desde 2005, o programa lança editais com a finalidade de apoiar projetos de criação ou reestruturação desses núcleos nas IFES. Os núcleos têm a responsabilidade de melhorar o acesso das pessoas com deficiência a todos os espaços, ambientes,

1 Site do Incluir: http://portal.mec.gov.br/programa-incluir 
ações e processos desenvolvidos na instituição, buscando integrar e articular as demais atividades para a inclusão educacional e social dessas pessoas.

O programa cumpre o disposto nos decretos $n^{0} 5.296 / 2004$ (que trata a acessibilidade) e $\mathrm{n}^{\mathrm{0}} 5.626 / 2005$ (que trata a Libras como componente curricular obrigatória) e no edital do Incluir 04/2008 (BRASIL, 2008) que, por meio dos núcleos de acessibilidade, garante acesso, permanência e combate barreiras físicas e atitudinais no ensino superior.

Em 2010, último ano de resultados apresentados pelo programa em sua página na internet, constatou-se que o MEC aprovou em todo o país 43 projetos: 5 na Região Norte e Centro-oeste, 11 na Região Nordeste, Sul e Sudeste. Observa-se, porém, que as universidades estaduais não estão contempladas com verbas do programa, o que dificulta a realização de serviços e à implantação de Núcleos de Acessibilidade em tais instituições.

Vale ressaltar que, apesar dos números e o aparente sucesso, o Programa Incluir ainda deve muito na prática. Nem todas as universidades foram contempladas com verba do programa, algumas, inclusive, por falta de propostas.

\section{Para onde seguir com a inclusão no ensino superior?}

A mutação do paradigma de compreensão da deficiência, de uma perspectiva biológica e individualizada (associada a ideias de incapacidade e de anormalidade) para uma perspectiva de construção social e simbólica, decorrente, quer da conexão estreita entre deficiência e práticas discriminatórias, quer da perpetuação de uma linguagem opressiva e desempoderante, contribuiu para a maior politização e conscientização sobre o fenômeno nas últimas duas décadas. O modelo de reabilitação associado a uma classificação das pessoas com deficiência como "especiais" criou, na verdade, ao longo do século XX, as condições para a individualização dos fatores causais e consequenciais da deficiência, bem como uma restrição do poder de decidir e de agir das pessoas com deficiência. A assunção de um modelo social para a compreensão da deficiência introduz, a partir dos anos 1990, a ideia de que a desvantagem se encontra, sobretudo, plasmada nas restrições criadas pelas instituições sociais, pouco sensibilizadas para as especificidades das pessoas com deficiência, tal como se encontrava já expresso no documento fundador da Union of Physical Impaired Against Segregation nos anos 1970 (UK, 1976). A conjugação dos dois modelos consubstancia hoje uma compreensão relacional e holística da deficiência com dimensões biológicas, psicoemocionais e sociais (WHO, 2002). 
A predominância - atribuída, ou não, a algum dos fatores - condiciona, porém, a concepção sobre a deficiência, e, consequentemente, o conjunto de medidas sociopolíticas que a ela se direcionam e que tem impactos evidentes e multidimensionais na vida das pessoas com deficiência.

A breve incursão, nas políticas de apoio social e de educação em Portugal e no Brasil, permite enfatizar um padrão de resposta às questões da deficiência e da inclusão que corresponde ao que vem a ser destacado em outros estudos (BARNES, 1991; DRAKE, 2001): uma centralidade no modelo de necessidades da pessoa com deficiência, numa lógica individualizada de ponderação prioritária do déficit e da dependência, em detrimento de uma abordagem mais social e institucional ou de uma política menos setorializada. Veja-se por exemplo o caso das políticas de emprego em Portugal que conduziram à "criação de subsídios para a integração de pessoas com deficiência em espaços laborais, em vez da criação de espaços laborais acessíveis para todas as pessoas" (FONTES, 2009 , p. 85). A perspectiva de igualdade de oportunidades que preconizamos, nomeadamente no acesso e na frequência do ensino superior, traduz-se, pois, numa concessão substancial e não meramente formal (na letra da lei) de acesso a direitos fundamentais.

No domínio educacional, as concessões de justiça distributiva centramse sobretudo, ora na igualdade de oportunidades, associada, numa ótica liberal estrita, a uma definição prévia de condições formais de acesso igualitárias, ora na chamada igualdade de resultados, numa perspectiva liberal mais radical, associada à avaliação de taxas de sucesso, para grupos diferenciados, e à consequente proposta de políticas de compensação, ou de diferenciação positiva, para os grupos que, em consonância com os parâmetros avaliados, se encontram em desvantagem (GEWIRTZ, 1998; ESTÊVÃO, 2002). Para o efeito, no que diz respeito ao acesso e à frequência do ensino superior para pessoas com deficiência, é essencial considerar uma perspectiva mais integrada e multidimensional sobre os fatores que podem ou não condicionar o sucesso educativo, seja em termos de acesso, seja em termos de frequência e de resultados. Por outras palavras, é preciso integrar perspectivas que ultrapassem, sem esquecer, as necessidades particulares das pessoas com deficiência e as suas "incapacidades", em prol de uma compreensão dos fatores sociais de assimetria de poder e das adaptações necessárias, nas instituições sociais, para assegurar uma igualdade de oportunidades substantiva.

Nesse sentido, há que pensar em políticas educativas que assegurem que as circunstâncias sociais e as condições de partida (biológicas, familiares, econômicas ou culturais) possam ser, se adversas ou constrangedoras, em grande medida neutralizadas no acesso à escola e à universidade e na frequência da mesma, mas também, políticas e práticas que assegurem a existência de oportunidades 
concretas no mundo social e no mercado de trabalho. A liberdade substancial, que entendemos como decorrente da igualdade substantiva de oportunidades, só existe se ultrapassar a mera retórica e se ancorar na existência de verdadeiras opções, o que implica que, para além de capacidades, as pessoas tenham oportunidade de as colocar em funcionamento (ALBUQUERQUE, 2015).

Portanto, as políticas educativas têm de ser pensadas em articulação com outras políticas de desenvolvimento. Por exemplo, se apenas existem medidas compensatórias que garantam a igualdade de acesso das pessoas com deficiência ao ensino superior, esquecem-se os fatores que continuam a condicionar a vida das pessoas e como tal a potenciar o insucesso e a discriminação. Preconiza-se, pois, o desenvolvimento de políticas educativas e de inserção verdadeiramente promocionais, não paternalistas, mas humanistas, prospectivas e não setorializadas. A promoção de uma igualdade de oportunidades substancial é, em suma, necessariamente multidimensional, envolvendo compromissos entre exigências múltiplas e princípios diversos que deveriam ser debatidos e reconstruídos num espaço público deliberativo no qual as pessoas com deficiência fossem parte integrante.

\section{REFERÊNCIAS}

ALBUQUERQUE, C. Contributos para uma reflexão crítica sobre a igualdade (substantiva) de oportunidades. In: ENS, R. T.; BONETI, L. W. (Ed.). Educação e Justiça Social. Ijuí: Editora Unijuí, 2015. p. 73-91.

BARNES, C. Disabled people in Britain and discrimination: a case for anti-discrimination. Londres: Hurst \& Company, 1991.

BRASIL. Constituição da República Federativa do Brasil. Brasília: Senado Federal, 1988. Disponível em: <http://www.planalto.gov.br/ccivil_03/constituicao/constituicaocompilado.htm>. Acesso em: 22 mar. 2017.

BRASIL. Decreto $n^{\circ} 3.298$, de 20 de dezembro de 1999. Regulamenta a Lei ${ }^{\circ} 7.853$, de 24 de outubro de 1989, dispõe sobre a Política Nacional para a Integração da Pessoa Portadora de Deficiência, consolida as normas de proteção, e dá outras providências. Diário Oficial da União, 21 dez. 1999. Disponível em: <http://www.planalto.gov.br/ ccivil_03/decreto/d3298.htm> Acesso em: 22 mar. 2017.

BRASIL. Decreto n ${ }^{\circ} 5.296$, de 2 de dezembro de 2004. Regulamenta as Leis ${ }^{\circ} 10.048$, de 8 de novembro de 2000 , que dá prioridade de atendimento às pessoas que especifica, e $\mathrm{n}^{\circ} 10.098$, de 19 de dezembro de 2000, que estabelece normas gerais e critérios básicos para a promoção da acessibilidade das pessoas portadoras de deficiência ou com 
mobilidade reduzida, e dá outras providências. Diário Oficial da União, 03 dez. 2004. Disponível em: <http:/www.planalto.gov.br/ccivil_03/_ato2004-2006/2004/decreto/ d5296.htm> Acesso em: 22 mar. 2017.

BRASIL. Decreto $n^{\circ} 5.626$, de 22 de setembro de 2005. Regulamenta a Lei ${ }^{\circ} 10.436$, de 24 de abril de 2002, que dispõe sobre a Língua Brasileira de Sinais - Libras, e o art. 18 da Lei no 10.098, de 19 de dezembro de 2000. Diário Oficial da União, 23 dez. 2005. Disponível em: <http://www.planalto.gov.br/ccivil_03/_ato2004-2006/2005/decreto/ d5626.htm>. Acesso em: 22 mar. 2017.

BRASIL. Lei Federal no 10.861 , de 14 de abril de 2004. Institui o Sistema Nacional de Avaliação da Educação Superior - SINAES e dá outras providências. Diário Oficial da União, 15 abr. 2004. Disponível em: <http://www.planalto.gov.br/ccivil_03/_ato20042006/2004/lei/110.861.htm>. Acesso em: 29 out. 2014.

BRASIL. Lei Federal no 11.096, de 13 de janeiro de 2005. Institui o Programa Universidade para Todos - PROUNI, regula a atuação de entidades beneficentes de assistência social no ensino superior; altera a Lei $n^{0} 10.891$, de 9 de julho de 2004, e dá outras providências. Diário Oficial da União, 14 jan. 2005. Disponível em: <http://www.planalto.gov.br/ccivil_03/_ato2004-2006/2005/lei/L11096.htm>. Acesso em: 22 mar. 2017.

BRASIL. Decreto Federal no 6.096, de 24 de abril de 2007. Institui o Programa de Apoio a Planos de Reestruturação e Expansão das Universidades Federais - REUNI. Diário Oficial da União, 25 abr. 2007. Disponível em: <http://www.planalto.gov.br/ ccivil_03/_Ato2007-2010/2007/Decreto/D6096.htm>. Acesso em: 22 mar. 2017.

BRASIL. Ministério da Educação. Edital nº 04. Programa de Acessibilidade na Educação Superior (Incluir). Diário Oficial da União, 5 de maio de 2008.

BRASIL. Lei Federal no 13.146, de 6 de julho de 2015. Institui a Lei de Inclusão da Pessoa com Deficiência. Diário Oficial da União, 07 jul. 2015. Disponível em: $<$ http:// www.planalto.gov.br/ccivil_03/_Ato2015-2018/2015/Lei/L13146.htm>. Acesso em: 22 mar. 2017.

CANDIDO PEREIRA, C. E. Inclusão no mercado de trabalho: analisando a relação escola e empregabilidade de pessoas com deficiências. Dissertação (Mestrado em Educação) - Programa de Pós-Graduação em Educação Escolar, Faculdade de Ciências e Letras, Universidade Estadual Paulista, Araraquara. 2010.

CANDIDO PEREIRA, C. E. Inclusão no ensino superior: percepções de servidores públicos docentes e não docentes no Brasil e em Portugal. Tese (Doutorado em Educação) - Programa de Pós-Graduação em Educação Escolar, Faculdade de Ciências e Letras, Universidade Estadual Paulista, Araraquara. 2016.

DRAKE, R. Welfare States and disabled people. In: G. L. Albrecht et al. (orgs.). Handbook of Disability Studies. Londres: Sage Publications, 2001. p. 412-426.

ESTÊVÃO, C. A. V. Justiça complexa e educação. Uma reflexão sobre a dialectologia da justiça em educação. Revista Crítica de Ciências Sociais, 64, p. 107-134, 2002. 
FONTES, F. Pessoas com deficiência e políticas sociais em Portugal: da caridade à cidadania social. Revista Crítica de Ciências Sociais, 86, p. 73-93, set. 2009.

GEWIRTZ, S. Conceptualizing social justice in education: Mapping the territory. Journal of Education Policy, v. 4, n. 13, p. 469-484, 1998.

HABERMAS, J. Facticidad y validez. Madrid: Trotta, 1998.

MITTLER, P. Educação Inclusiva: contextos sociais. Porto Alegre: Artmed, 2003.

MOEHLECKE, S. Ações Afirmativas no ensino superior: entre a excelência e a justiça racial. Educação e Sociedade, Campinas, v. 25, n. 88, especial, out. 2004. Disponível em: <http://www.scielo.br/pdf/es/v25n88/a06v2588.pdf>. Acesso em: 29 out. 2014.

PORTUGAL. Constituição da República Portuguesa de 1976. Lisboa. 25 de abril de 1976.

PORTUGAL. Lei $n^{\circ}$ 46, de 14 de outubro de 1986. Lei de Bases do Sistema Educativo. Lisboa.

PORTUGAL. Lei $n^{\circ}$ 9, de 02 de maio de 1989. Lei de Bases da Prevenção e da Reabilitação e Integração das Pessoas com Deficiência. Lisboa.

PORTUGAL. Lei $n^{\circ} 38$, de 18 de agosto de 2004. Bases Gerais do Regime Jurídico da Prevenção, Habilitação, Reabilitação e Participação da Pessoa com Deficiência. Lisboa.

PORTUGAL. Leis e Decretos. $1^{\circ}$ Plano de Acção para a Integração das Pessoas com Deficiências ou Incapacidade. Setembro de 2006. Lisboa.

PORTUGAL. Leis e Decretos. Decreto-Lei no 56, de 03 de março de 2009.

PORTUGAL. Leis e Decretos. Despacho n ${ }^{\circ}$ 7031-B/2015, 24 de junho de 2015. Ministério da Educação e Ciência.

SANTOS, S. A. Ações afirmativas e combate ao racismo nas américas. Brasília: Ministério da Educação: UNESCO, 2005.

SASSAKI, R. K. Inclusão: construindo uma sociedade para todos. Rio de Janeiro: WVA, 2006.

TURMUSANI, M. Work and adulthood: economic survival in the majority world. In: Mark Priestley (org.). Disability in the life course: Global Perspectives. Cambridge: Cambridge University Press, 2002. p. 192-205.

UK. Fundamental principles of disability. Londres: UPIAS, 1976.

WHO. International classification of functioning and disability. Geneva: World Health Organisation, 2002.

Texto recebido em 31 de maio de 2017.

Texto aprovado em 02 de junho de 2017. 
